\title{
Electrospun nanofiber blend with improved mechanical and biological performance
}

This article was published in the following Dove Press journal:

International Journal of Nanomedicine

\author{
Anderson Oliveira Lobo, ${ }^{1-4}$ \\ Samson Afewerki, ${ }^{3,4}$ Mirian \\ Michele Machado de Paula, ${ }^{5}$ \\ Paria Ghannadian, ${ }^{5}$ Fernanda \\ Roberta Marciano, ${ }^{2,5}$ Yu Shrike \\ Zhang, ${ }^{3,4}$ Thomas Jay Webster, ${ }^{5}$ Ali \\ Khademhosseini ${ }^{3,4,6-10}$
}

'LIMAV-Interdisciplinary Laboratory for Advanced Materials, PPGCM-Materials Science and Engineering Graduate Program, UFPI-Federal University of Piauí, Teresina, Piauí, CEP 64049-550, Brazil; ' Institute of Science and Technology, Brasil University, São Paulo, CEP 08230-030, Brazil; ${ }^{3}$ Division of Engineering in Medicine, Department of Medicine, Brigham and Women's Hospital, Harvard Medical School, Cambridge, MA 02139 , USA; ${ }^{4}$ Harvard-MIT Division of Health Sciences and Technology, Massachusetts Institute of Technology, Cambridge, MA 02139, USA; ${ }^{5}$ Department of Chemical Engineering, Northeastern University, Boston, MA 02। I5, USA; ${ }^{6}$ Department of Bioengineering, Department of Chemical and Biomolecular Engineering, Henry Samueli School of Engineering and Applied Sciences, University of California-Los Angeles, Los Angeles, CA 90095, USA; ${ }^{7}$ Department of Radiology, David Geffen School of Medicine, University of California-Los Angeles, Los Angeles, CA 90095, USA; ${ }^{8}$ Center for Minimally Invasive Therapeutics (C-MIT), University of California-Los Angeles, Los Angeles, CA 90095, USA; ' $\mathrm{C}$ alifornia NanoSystems Institute (CNSI), University of California-Los Angeles, Los Angeles, CA 90095, USA; ${ }^{10}$ Department of Bioindustrial Technologies, Konkuk University, Seoul |43-70|, Republic of Korea

Correspondence: Anderson Oliveira Lobo Interdisciplinary Laboratory for Advanced Materials, Materials Science and Engineering Graduate Program, UFPI-Federal University of Piauí, Teresina, PI, CEP 64049-550, Brazil Email lobo@ufpi.edu.br

Samson Afewerki

Division of Engineering in Medicine, Department of Medicine, Brigham and Women's Hospital, Harvard Medical School, Cambridge, MA 02139, USA

Email samson.afewerki20@gmail.com
Background: Here, electrospun fibers based on a blend of polycaprolactone (PCL), poly(ethylene glycol) (PEG), and gelatin methacryloyl (GelMA) were developed. The careful choice of this polymer combination allowed for the preparation of a biomaterial that preserved the mechanical strength of PCL, while at the same time improving the hydrophilicity of the blended material and human osteoblast maturation.

Methods: The morphology, chemical structure, wettability, and mechanical properties before and after UV photocrosslinking were evaluated. Furthermore, human osteoblasts (hFOB) were cultivated for up to 21 days on the scaffolds, and their potential to upregulate cell proliferation, alkaline phosphatase (ALP) activity, and calcium deposition were investigated.

Results: Contact angle measurement results showed that the developed scaffolds presented hydrophilic properties after PEG and GelMA incorporation before $\left(25^{\circ}\right)$ and after UV photocrosslinking $\left(69^{\circ}\right)$ compared to pure PCL $\left(149^{\circ}\right)$. PCL:PEG:GelMA-UV displayed a slight increase in mechanical strength (elastic modulus $\sim 37 \mathrm{MPa}$ ) over PCL alone ( $\sim 33 \mathrm{MPa})$. Normally, an increase in strength of fibers leads to a decrease in elongation at break, due to the material becoming less deformable and stiffer, thus leading to breaks at low strain. This behavior was observed by comparing PCL (elongation at break 106\%) and PCL:PEG:GelMA-UV ( 50\%). Moreover, increases in ALP activity (10-fold at day 14) and calcium deposition (1.3-fold at day 21) by hFOBs were detected after PEG and GelMA incorporation after UV photocrosslinking compared to pure PCL. Ultrathin and hydrophilic fibers were obtained after PEG and GelMA incorporation after UV photocrosslinking, but the strength of PCL was maintained. Interestingly, those ultrathin fiber characteristics improved hFOB functions.

Conclusion: These findings appear promising for the use of these electrospun scaffolds, based on the combination of polymers used here for numerous orthopedic applications.

Keywords: biomaterials, electrospinning, human osteoblasts, mechanical properties, wettability, bone regeneration

\section{Introduction}

Ultrathin scaffolds with desirable mechanical and wettability properties for tissue engineering and biomedical applications remain challenging. ${ }^{1}$ These properties are able to control biological interactions with the scaffolds such as cell adhesion (controlling specific proteins), proliferation, and differentiation. ${ }^{2}$ In this context, polycaprolactone (PCL) has been largely used in bone tissue engineering applications. ${ }^{3} \mathrm{PCL}$ has favorable mechanical properties compared to other polyesters and has good biocompatibility. PCL has a tensile strength ranging from 10.5 to $16.1 \mathrm{MPa}$ and a tensile yield strength between 8.2 and 10.1 MPa. For electrospun PCL, the mean value of the Young's modulus has been reported to be 3.5-6 MPa, with an average value of the strain at break of $150-190 \%{ }^{4,5}$ However, PCL exhibits hydrophobic characteristics and a long degradation time, which may reduce 
cell adhesion and limit applications where faster erosion of the matrices is needed. For this reason, the development of new strategies for improving its hydrophilicity, degradability, osteogenesis, and controllable mechanical properties for orthopedic applications is needed. ${ }^{6-8}$

The optimal scaffold for bone regeneration should display sufficient mechanical properties to support bone tissue requirements (Young's modulus of cortical bone $=$ 15-20 GPa and 0.1-2 GPa for cancellous bone), ${ }^{9}$ hydrophilicity to improve the infiltration of cells favoring the transportation of water, nutrients, and waste, as well to promote osteogenesis. ${ }^{10}$

One strategy to design such a biomaterial that fulfills the above requirements is to combine different polymers in a way that synergizes their desirable, unique properties without reducing their efficacy. Such materials can be used for the fabrication of biomaterial fibers (to mimic the extracellular matrix [ECM] and enhance the surface contact) for bone tissue regeneration through the employment of electrospinning. ${ }^{11}$ There are several advantages with this approach compared to other methods, specifically for preparing polymer blends, such as reproducibility, low cost, and high yield. ${ }^{12}$ Electrospinning is simple and efficient, since a common solvent can be used to dissolve different polymers, and the solvent can be easily evaporated due to applied high voltage. $^{12}$

An additional polymer that is of great interest in this context is poly(ethylene glycol) (PEG) that has distinct properties such as biocompatibility, water absorption, hydrophilicity, and the ability to reduce protein adsorption. ${ }^{13}$ There have been several reports on the combination of PCL and PEG, ${ }^{14,15}$ PCL and gelatin, $, 45,8,16$ and PCL/PEG/gelatin for bone tissue regeneration (in these examples noncrosslinkable gelatin was employed). ${ }^{17}$ These reports have described that electrospun PCL, PEG, and gelatin fibers and their combinations improved the osteogenesis and calcification of the matrix, induced osteoblast maturation and promoted bone regeneration; however, the described combinations resulted in a lower tensile strength (ranging from 2 to $35 \mathrm{MPa}$ ) compared to scaffolds for bone regeneration. .,8,16 $^{5}$ For example, Tiwari et $\mathrm{al}^{18}$ combined PCL and PEG to produce scaffolds, and obtained an average tensile stress of up to $29 \mathrm{MPa}$.

The produced scaffold should also promote cell adhesion for better interaction with the host tissue. Gelatin, a natural polymer, is a good candidate for promoting cell adhesion due to a similarity to the ECM. ${ }^{19}$ A photocrosslinkable gelatin methacryloyl (GelMA) material has been extensively used as a hydrogel scaffold for biomaterial applications. ${ }^{19}$ GelMA has a chemical similarity to numerous ECMs and has been shown to improve vascularization, water absorption, and permeability of proteins, and possess a fast and controlled degradability. ${ }^{20}$ However, GelMA has relatively weak mechanical properties for bone tissue engineering applications. To overcome this limitation, GelMA may be combined with other materials for the design of scaffolds suitable for those applications..$^{21,22}$ The measured Young's modulus for GelMA fibers alone (GelMA [10 wt\%], 70\% degree of methacryloyl modification, 2-10 min of UV crosslinking time) ranges from 290 to $350 \mathrm{kPa}$ and its elongation at break is between 51 and $67 \% .{ }^{23}$ Herein, we combined PCL, PEG, and GelMA, followed by an electrospinning process for the design of fibrous blend scaffolds, as a suitable candidate for bone tissue engineering. The produced ultrathin fibers showed hydrophilicity and high mechanical strength while in vitro osteoblast functions were improved. Our study, thus, showcases the applications of this new scaffolding system for bone tissue regeneration, with a potential of extending to engineering other functional tissue types.

\section{Results and discussion}

The GelMA was prepared by methacryloyl substitution of gelatin, and the degree of substitution was determined using proton nuclear magnetic resonance $\left({ }^{1} \mathrm{H} \mathrm{NMR}\right)$ analysis ( $70 \%$ yield, 66\% degree of substitution, Figure 1A and B). ${ }^{24}$ Moreover, it is widely known that low molecular weight PEG alone is challenging to electrospin. ${ }^{25}$ However, this can be circumvented by a combination with other biomaterials; moreover, low amounts of PEG can be used to introduce hydrophilicity. ${ }^{26}$ Notably, since PEG is known to be cell-repellent, an optimal concentration between PEG and GelMA is an important balance between hydrophilicity and cell adhesion. However, it has previously been reported that only an addition of $5 \mathrm{w} / \mathrm{v} \%$ GelMA to PEG (20 w/v\%) improved cell adhesion. ${ }^{24}$

The prepared solutions and their concentrations for electrospinning are depicted in Figure $1 \mathrm{C}$, based on previous reports. ${ }^{18}$ Electrospinning of a PCL, PEG, and GelMA blend, followed by further crosslinking, provides a covalentlybonded hybrid mat, as illustrated in Figure 1D.

The morphology was investigated through scanning electron microscopy (SEM) analysis (Figure 2). The microfibrous mats made from PCL displayed fiber diameters of $2.63 \pm 0.78 \mu \mathrm{m}$ (Figure $\mathrm{S} 1 \mathrm{~A}-\mathrm{C}$ and $\mathrm{J}$ ). As expected, the electrospinning of pure PEG did not produce fibers, instead only beads were obtained (Figure S1G-I). However, when 
A

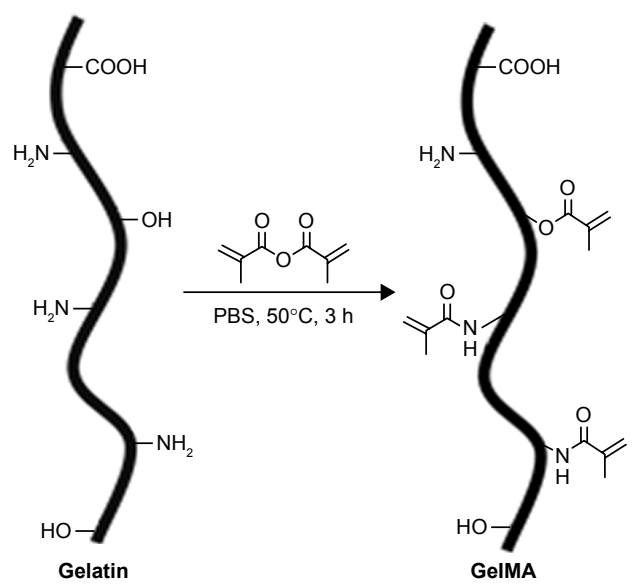

C

\begin{tabular}{cccc}
\hline aEntry & PCL (wt \%) & PEG (wt \%) & GeIMA (wt \%) \\
\hline 1 & 100 & - & - \\
2 & 60 & 40 & - \\
3 & 60 & 30 & 10 \\
$4^{\mathrm{b}}$ & 60 & 30 & 10 \\
\hline
\end{tabular}

B

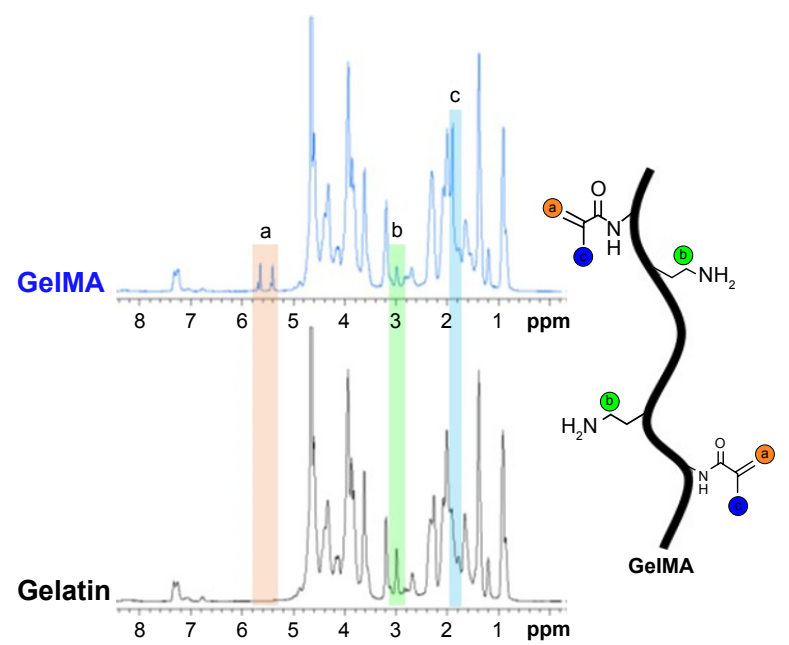

D

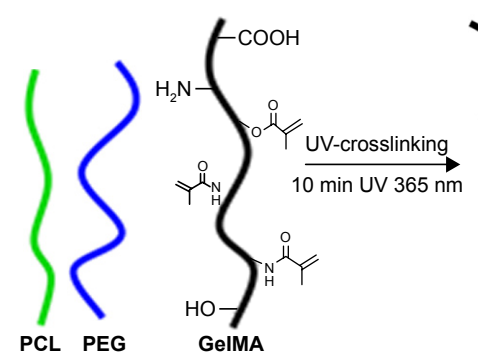

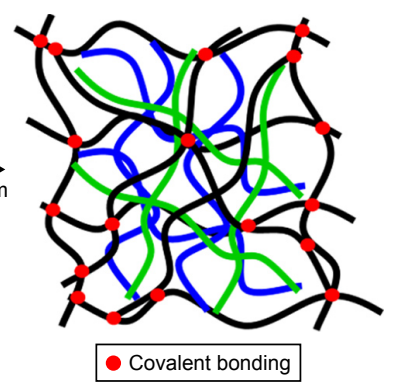

Figure I (A) Preparation of GelMA. Gelatin containing primary amino $\left(-\mathrm{NH}_{2}\right)$ and hydroxyl $(-\mathrm{OH})$ groups was reacted with methacrylic anhydride to add methacryloyl pendant groups. (B) 'H-NMR of the prepared GelMA compared to gelatin. (C) The different solutions prepared for the photocrosslinking step after electrospinning. (D) Scheme illustrating the chemistry and possible interactions between the electrospun polymers after photocrosslinking.

Notes: aFor all the solutions hexafluoroisopropan-2-ol (HFIP) was employed and the final volume was $5 \mathrm{~mL}$. ${ }^{\mathrm{b}}$ The photoinitiator lithium phenyl (2,4,6-trimethylbenzoly) phosphinate was added to the mixture to crosslink the prepolymer.

Abbreviations: GelMA, gelatin methacryloyl; 'HNMR, proton nuclear magnetic resonance.

PCL and PEG were combined, ultrathin fibrous mats were obtained (Figure $2 \mathrm{~A}-\mathrm{C}$ ), which presented diameter distributions of $0.39 \pm 0.14 \mu \mathrm{m}$ (Figure $2 \mathrm{~J}$ ). The electrospun mats made of pure GelMA provided ultrathin smooth fibers with a diameter of $0.18 \pm 0.02 \mu \mathrm{m}$ (Figure S1D-F and K) and, by combining PCL, PEG, and GelMA, ultrathin fibers with a similar morphology were obtained (Figure 2D-F) with a fiber diameter of $0.42 \pm 0.17 \mu \mathrm{m}$ (Figure $2 \mathrm{~K}$ ). Importantly, subsequent UV crosslinking of the fiber changed neither its morphology (Figure 2G-I) nor diameter $(0.43 \pm 0.17 \mu \mathrm{m}$, Figure 2L).

Fourier-transform infrared spectroscopy (FTIR) analysis identified functional groups and interactions of the polymers within the fibers (Figure $3 \mathrm{~A}$ and $\mathrm{B}$ ). The main peaks for the PCL:PEG:GelMA electrospun mats related to each polymer component were clearly identified (Figure 3A and B). The main peaks referred to PCL were indexed, as follows: $1,724 \mathrm{~cm}^{-1}$ ( $\mathrm{C}=\mathrm{O}$ stretching), 1,342 $\mathrm{cm}^{-1}\left(\mathrm{CH}_{2}\right.$, bending), $1,240 \mathrm{~cm}^{-1}$ (asymmetric C-O-C stretching), 1,190 $\mathrm{cm}^{-1}$ (O-C-O stretching), 1,170 $\mathrm{cm}^{-1}$ (C-O-C stretching),
$1,157 \mathrm{~cm}^{-1}$ (C-C stretching), and $731 \mathrm{~cm}^{-1}\left(-\left(\mathrm{CH}_{2}\right) n\right.$, bending). ${ }^{26,27}$ The GelMA presence was observed due to the presence of amide $\mathrm{I}\left(1,637 \mathrm{~cm}^{-1}, \mathrm{C}=\mathrm{O}\right.$ stretching $), 1,634$ (methacryloyl group, $\mathrm{C}=\mathrm{C}$, stretching), amide II $\left(1,529 \mathrm{~cm}^{-1}\right.$, $\mathrm{N}-\mathrm{H}$ bending), and amide III $\left(1,448 \mathrm{~cm}^{-1}\right.$, vibrations of $\mathrm{C}-\mathrm{N}$ and $\mathrm{N}-\mathrm{H}){ }^{28}$ The presence of PEG was also identified: $839 \mathrm{~cm}^{-1}$ (C-H, bending), $951 \mathrm{~cm}^{-1}\left(\mathrm{CH}_{2}\right.$, rocking), and $1,115 \mathrm{~cm}^{-1}$ (C-O, stretching). ${ }^{29,30}$

FTIR was also used to examine the potential differences after UV crosslinking (Figure 3B). The band at 1,634 $\mathrm{cm}^{-1}$ could be related to the presence of $\mathrm{C}=\mathrm{C}$ double bonds in the scaffolds before UV irradiation (Figure 3B). ${ }^{31}$ Nevertheless, this band disappeared after UV irradiation, indicating the success of the crosslinking procedure (Figure 3B). The effect of the formation of a physical network with increasing subsequent chemical crosslinking efficiency has also been reported previously. ${ }^{21}$

Additionally, the mechanical properties of the electrospun scaffolds before and after crosslinking were investigated (Figure 3C and D). The designed PCL:PEG:GelMA 

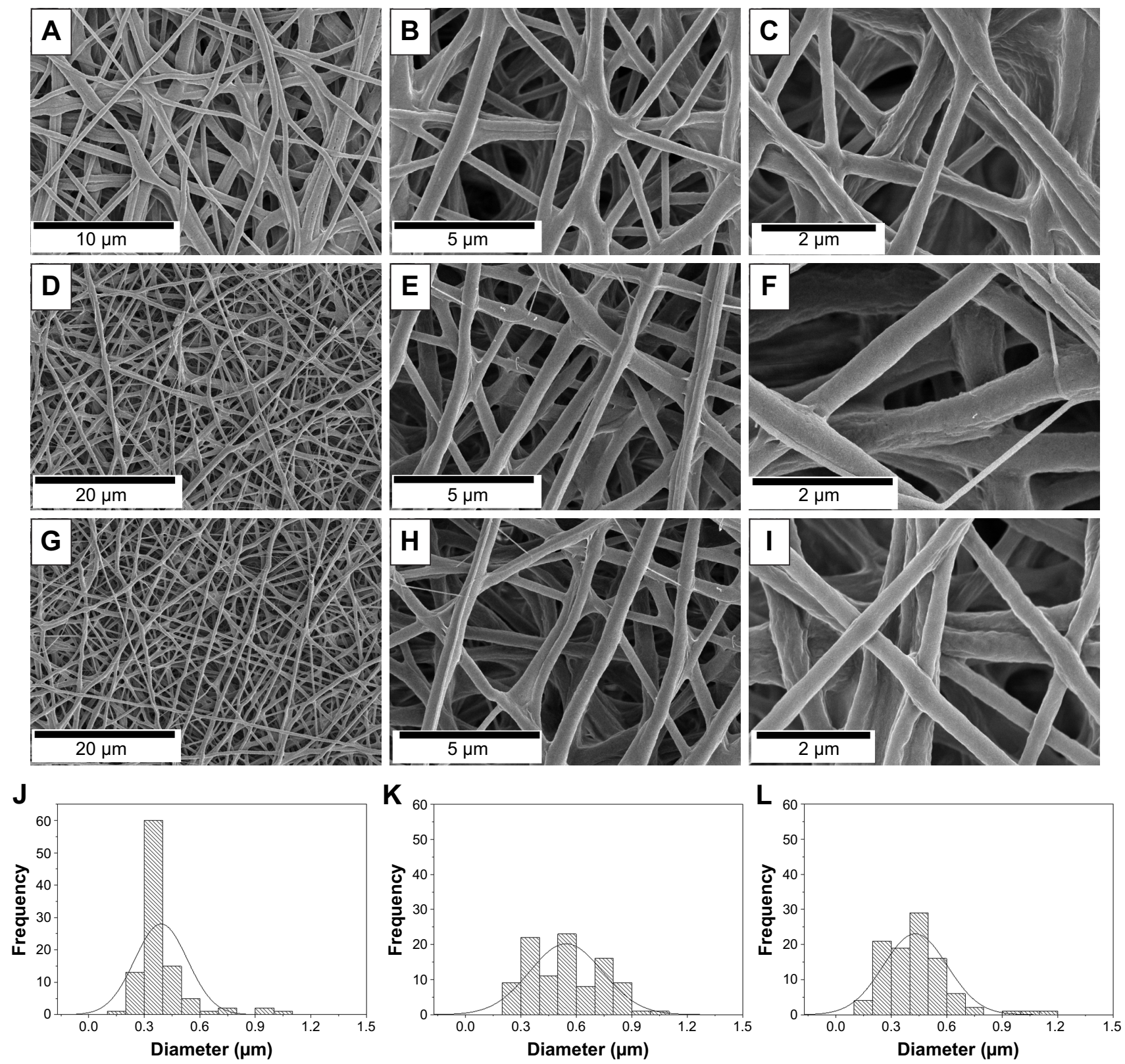

Figure 2 (A-I) Morphology of electrospun fibers from the SEM analysis: (A-C) PCL-PEG, (D-F) PCL-PEG-GelMA, and (G-I) PCL-PEG-GelMA-UV fibers. (J-L) The distribution of the fiber diameters for (J) PCL-PEG, (K) PCL-PEG-GelMA, and (L) PCL:PEG:GelMA-UV fibers.

Abbreviations: GelMA, gelatin methacryloyl; PCL, polycaprolactone; PEG, poly(ethylene glycol); SEM, scanning electron microscopy.

scaffold showed a high elastic modulus after UV photocrosslinking compared to the other scaffolds without photocrosslinking, resulting in an elastic modulus of $\sim 37 \mathrm{MPa}$ (PCL:PEG:GelMA-UV), which was in a similar range to that of PCL ( $\sim 33 \mathrm{MPa})$. In contrast, the measured elastic moduli for the PCL:PEG scaffold were $\sim 21.2 \mathrm{MPa}$ and $\sim 18.85 \mathrm{MPa}$ for the PCL:PEG:GelMA scaffolds without photocrosslinking (Figure 3C).

As expected, the elongation at break for the PCL:PEG: GelMA-UV mats $(\sim 50 \%)$ was lower than those of all the other samples, probably due to the stiffer polymer obtained after UV crosslinking (Figure 3D). However, the PCL:PEG blends presented a superior elongation property $(\sim 283 \%)$ than that of pure PCL ( 106\%) (Figure 3D). However, after incorporation of GelMA, the value decreased by a factor of $2(\sim 144 \%)$, most likely due to the fragility of gelatin compared to PCL and PEG.

Recently, Tiwari et a $1^{18}$ measured similar values between PCL and PCL:PEG mats. However, herein, the mechanical properties measured after the incorporation of GelMA and further UV photocrosslinking (PCL:PEG:GelMA-UV) provided a value 3 -fold greater than that already reported 
A

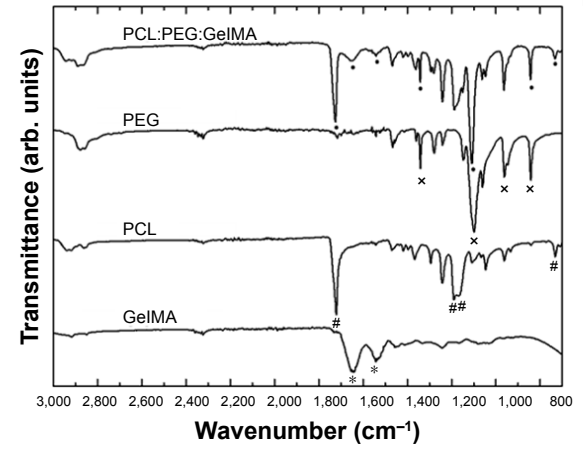

C

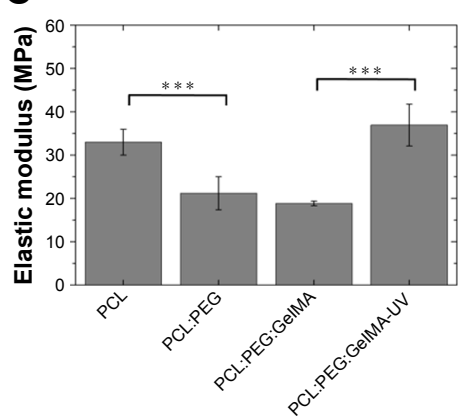

$\mathbf{F}$

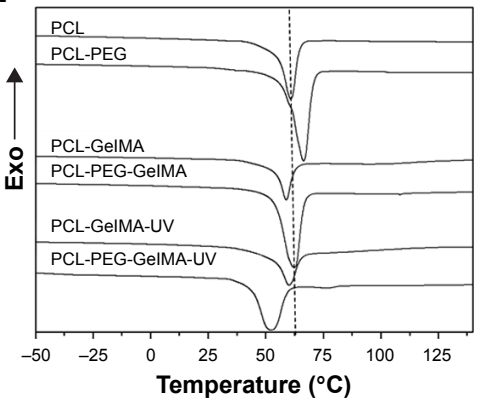

B

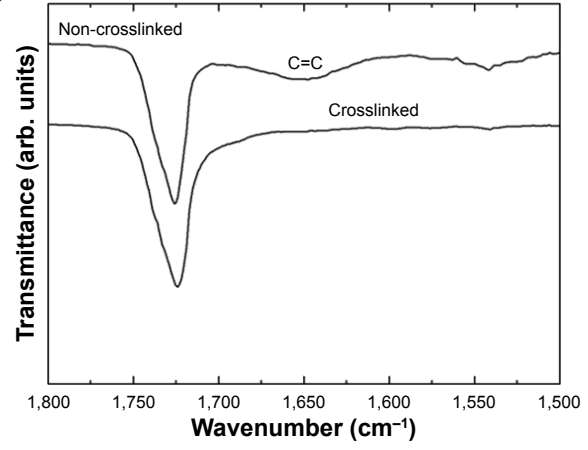

D

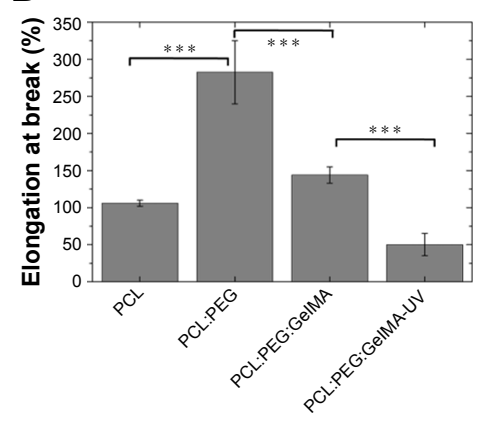

G

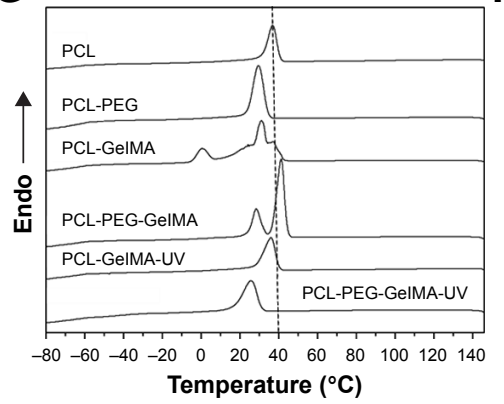

$\mathbf{E}_{250}$

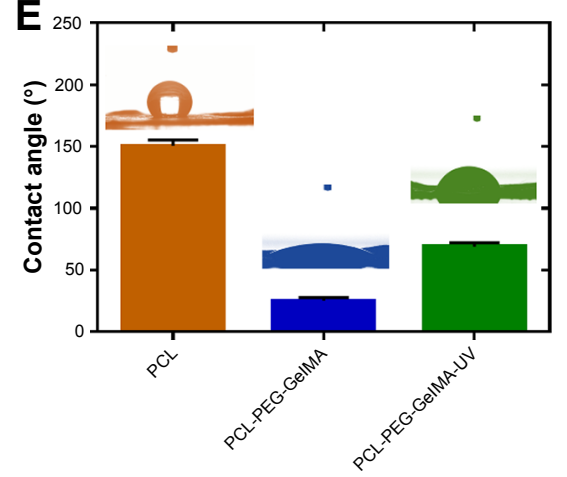

H

\begin{tabular}{llll}
\hline Material & $\boldsymbol{T m}\left({ }^{\circ} \mathrm{C}\right)$ & $\Delta \boldsymbol{H m}(\mathrm{J} / \mathbf{g})$ & $\boldsymbol{X c ( \% )}$ \\
\hline PCL & 60.94 & 66.01 & 43.5 \\
PCL:PEG & 66.52 & 117.7 & 77.6 \\
PCL:GeIMA & 58.92 & 48.54 & 32 \\
PCL:PEG:GeIMA & 62.43 & 93.51 & 61.6 \\
PCL:GeIMA-UV & 60.05 & 48.93 & 32.2 \\
PCL:PEG:GeIMA-UV & 51.74 & 61.38 & 40.5 \\
\hline
\end{tabular}

Figure 3 (A, B) FTIR spectra collected of the developed scaffolds: (A) indexed peaks identified by different symbols, (B) C=C bond before and after UV irradiation. (C, D) The mechanical analysis of the electrospun scaffolds: (C) elastic modulus and (D) elongation at break. The values are expressed as means and $S D s(* * * P 0.00 I$, $n=3$ ). (E) The contact angles measured and images of the water drops on the PCL, PCL:PEG:GelMA, and PCL:PEG:GelMA-UV. (F, G) The DSC thermograms of the fibers: (F) first heating cycle and $(\mathbf{G})$ first cooling cycle. $(\mathbf{H})$ The thermal analysis of all the fiber components analyzed providing the $T_{\mathrm{m}}$ (crystalline melting temperature), $\Delta H_{\mathrm{m}}$ (melting enthalpy), $\Delta H_{c}$ (crystallization enthalpy) and $X_{c}$ (fiber crystallinity). All the calculated $X_{c}$ belongs to the PCL in the mat, thus only the $100 \% \Delta H_{m}=$ melting enthalpy of a $100 \%$ crystalline PCL employed.

Abbreviations: FTIR, Fourier-transform infrared spectroscopy; GelMA, gelatin methacryloyl; PCL, polycaprolactone; DSC, differential scanning calorimetry; PEG, poly(ethylene glycol).

for bone tissue engineering applications (Figure 3C). .2-38 $^{32}$ Scaffolds based on different amounts of PCL, GelMA, and gelatin have been reported by Correia et al..$^{39}$ They had covered PCL mats with GelMA and gelatin previously, but here our process is more homogenous and easy to reproduce, because PCL and GelMA were electrospun together, followed by photocrosslinking, which greatly improves the mechanical properties of the scaffolds. Clearly, the prepared scaffolds presented a good synergy between PCL and GelMA. Recently, Zhao et al ${ }^{23}$ electrospun a GelMA solution and obtained ultrathin fibers $(700-1,400 \mathrm{~nm})$. The authors also investigated the mechanical properties of GelMA mats before and after UV curing. Herein, we combined PCL,
PEG, and GelMA and compared the crosslinking with/ without immersion of mats into the photoinitiator solution. The electrospun mats produced here had superior properties compared to other similar studies due to our unique combination of the selected polymers. Specifically, there was a clear improvement of the mechanical strength for our study (our results: $36.95 \pm 4.85 \mathrm{MPa}$; reported results: $400 \mathrm{kPa}$ ). ${ }^{39}$

Moreover, the hydrophilicity of the designed electrospun was improved by the addition of PEG and GelMA before and after UV comparable to PCL $\left(149^{\circ}\right.$ ) (Figure 3E). In this aspect, the hydrophilicity can be monitored by the comparison of the wettability and surface energy of the material, where a higher surface energy generally corresponds to a 
lower contact angle. ${ }^{40}$ The uncrosslinked material provided a water contact angle (CA) of $\sim 25^{\circ}$ and a surface energy of $71.4 \mathrm{~mJ} / \mathrm{m}^{2}$, while crosslinking resulted in a CA of $\sim 69^{\circ}$ and surface energy of $53.3 \mathrm{~mJ} / \mathrm{m}^{2}$ (Table S2).

It is known that a surface is hydrophobic when the $\mathrm{CA}>90^{\circ}$ and is hydrophilic when $\mathrm{CA}<90^{\circ} .{ }^{41}$ Correia et $^{39}$ coated GelMA, PEG acrylate (PEGA), and PEG diacrylate (PEGDA) onto PCL mats for the preparation of a more hydrophilic material, where they obtained $\mathrm{CA}$ that ranged from $\sim 40^{\circ}$ to $120^{\circ}$. Different in our approach, we perform a direct incorporation of the various biomaterials, whereas in the presented coating strategy, it required an extra step for the addition of GelMA. Prominently, coating processes can sometimes be limited due to debonding of the coating, mechanically fragility, and instability of the material, thus all avoided by direct incorporation. ${ }^{42}$

Zhao et $\mathrm{al}^{23}$ obtained a highly porous and water absorbable GelMA and GelMA:PLGA scaffolds suitable for wound healing applications. In our case, we improved the wettability and mechanical properties of the scaffolds favoring the adhesion and growth of osteoblasts.

Differential scanning calorimetry analyzed the thermal parameters, such as crystallization temperature $\left(T_{c}\right)$, melting temperature $\left(T_{\mathrm{m}}\right)$, enthalpy of fusion $\left(\Delta H_{\mathrm{m}}\right)$, enthalpy of crystallization $\left(\Delta H_{\mathrm{c}}\right)$, and degree of crystallinity $\left(X_{\mathrm{c}}\right)$ of the materials (Figure $3 \mathrm{~F}-\mathrm{H}$ ). The crystallization behavior of PCL after the addition of GelMA slightly shifted to a higher temperature, and $X_{\mathrm{c}}, \Delta H_{\mathrm{c}}$, and $\Delta H_{\mathrm{m}}$ increased significantly from $36.6 \%, 39.71$, and $93.84 \mathrm{~J} / \mathrm{g}$ to $83.2 \%$, and 69.01-142.9 J/g, respectively. However, the degree of crystallinity of the sample containing both PEG and GelMA was similar to pure PCL (Figure 3F and G). Noteworthy, after incorporation of PEG, extra peaks were obtained in the cooling cycle corresponding to the PEG moiety. It has previously been reported that a blend between PCL and PEG is highly dependent on the amount of each component in the blend and, in some cases, immiscibility and phase separation between PCL and PEG can occur, confirmed by extra peaks. ${ }^{41}$

In comparison, after crosslinking, a shift to a lower temperature was immediately observed (Figure $3 \mathrm{~F}$ and $\mathrm{G}$ ), however, all of the parameters $\left(X_{c}, \Delta H_{c}\right.$, and $\left.\Delta H_{m}\right)$ increased significantly comparable to the PCL fibers $\left(X_{c}=73.5 \%\right.$ and $85.8 \%, \Delta H_{c}=47.69$ and $50.44 \mathrm{~J} / \mathrm{g}$, and $\Delta H_{m}=113$ and $126.6 \mathrm{~J} / \mathrm{g}$, respectively, Figure $3 \mathrm{H}$ ). The result clearly confirms that the crosslinking induces crystallinity in the blend fibers, due to the improved network between the polymers (Figure 3H).
The biological activity (alkaline phosphatase [ALP] activity, calcium deposition, and cell proliferation) of the fabricated electrospun mat was studied for potential applications in bone tissue regeneration (Figure $4 \mathrm{~A}-\mathrm{C}$ ). ALP is a widely used and a classical biomarker to identify osteoblast differentiation (ECM mineralization). Therefore, when high expression is observed, it can be correlated to bone-forming protein expression during osteogenic differentiation, inducing mineralization promoted by a scaffold..$^{43}$ Interestingly, the groups containing GelMA increased ALP activity, calcium deposition, and osteoblast proliferation to a larger extent compared to pure PCL (Figure $4 \mathrm{~A}-\mathrm{C}$ ). The scaffolds showed an increase in ALP expression compared to PCL $(P<0.0001$, Figure 4A). At day 7, PCL:PEG:GelMA scaffolds had higher values compared to pure PCL and PCL:PEG $(P<0.0001)$.

The PCL scaffolds partially induced extracellular calcification at days 14 and 21. On the other hand, when PEG and GelMA were added, the values increased independent of the time points $(P<0.01)$. This highlights the favorable synergistic effect of the $-\mathrm{OH}$ groups on $\mathrm{PEG}$ and favorable amino acid moieties present in GelMA. At day 21, the ALP activity of the cells on the PCL:PEG scaffolds was 4-fold higher than that of the cells on pure PCL. At the same time (day 21), the ALP activity of cells on the PCL:PEG:GelMA scaffolds were 1.3-fold higher than that of the cells on the PCL:PEG scaffolds, and $\sim 5$-fold higher than that of the cells on the pure PCL scaffolds.

Additionally, Figure 4B illustrates the calcium deposition for all the analyzed groups. Calcium deposition is considered the final stage of osteoblast maturation to form bone. This may be because of the hydrophilic behavior associated with the ECM-like components in the GelMA chemical structure. It is also known that lower ALP levels are related to higher calcium deposition due to the last stage of maturation. ${ }^{44}$ This behavior matched the lowered ALP activity obtained up to 14 days, while the calcium deposition increased at the same time point (Figure 4A and B). Moreover, the lower value measured for the control (cells in the absence of any scaffold) further supports the hypothesis that our scaffold promotes calcium deposition. After days 7 , 14 , and 21, all the groups analyzed induced high levels of calcium deposition.

Cell proliferation was measured, and all the groups containing GelMA and PEG were compared to pure PCL nanofibers (Figure 4C). An increase in cell proliferation was observed, independent of the scaffolds. However, an enhancement was observed for groups containing PEG compared to pure PCL for all time points (Figure 4C). After 
A
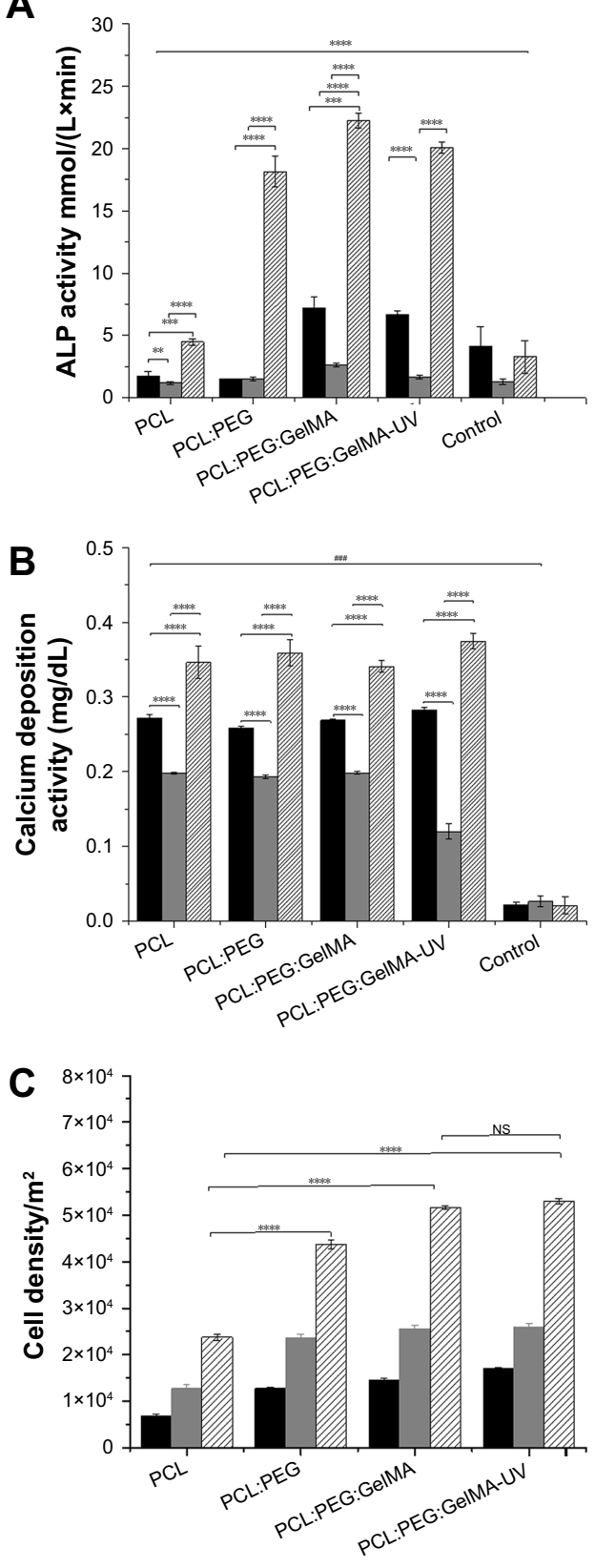

7 days 14 days 21 days
D
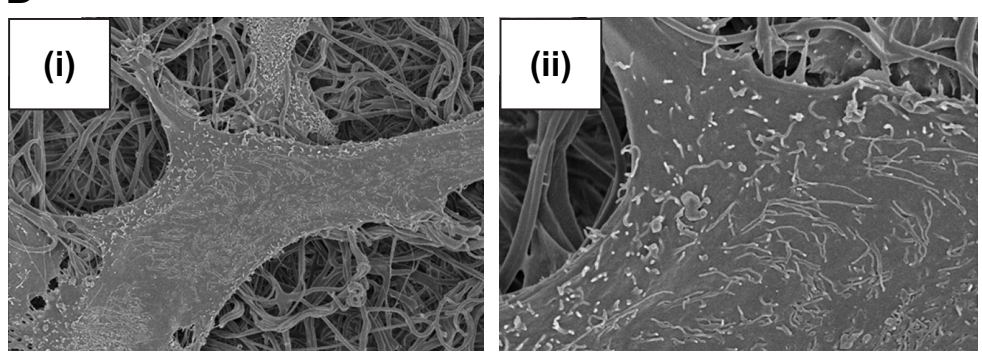

E
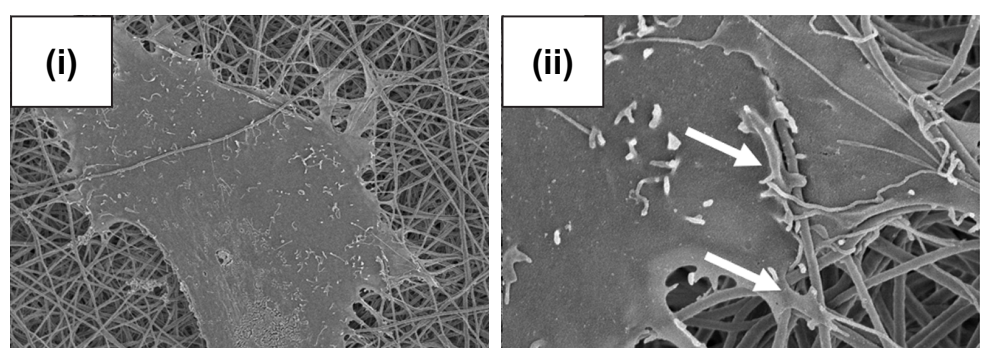

$\mathbf{F}$
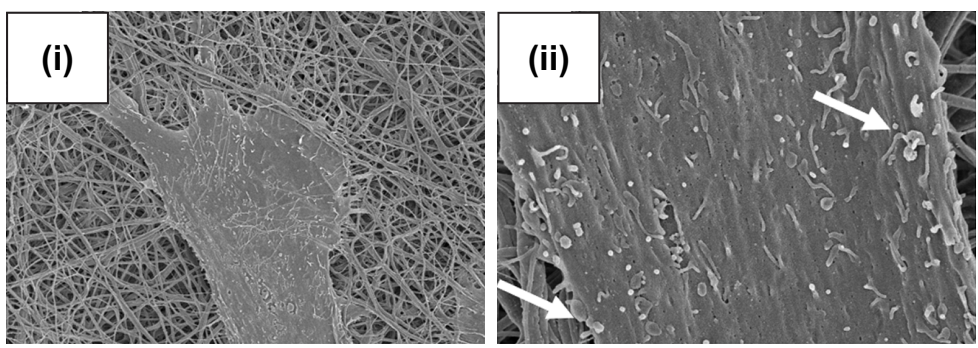

G
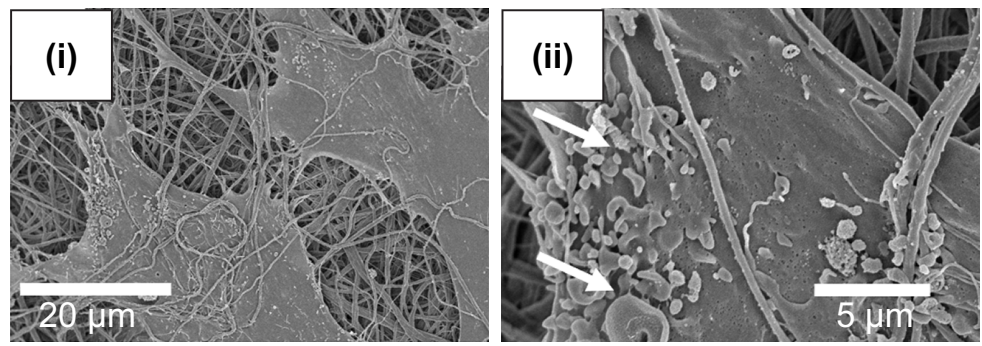

Figure 4 (A) ALP activity showed an increase of calcification of the extracellular matrix after inclusion of GelMA. (B) Calcium deposition demonstrated a further influence of GelMA to enhance the functions of osteoblasts. (C) MTS assay showing that osteoblastic cells were further influenced by hydrophilic properties after inclusion of PEG and GelMA. Data plotted in mean and SD $(\mathrm{N}=5)$. Values of $P<0.01$ were considered significant. Data were normalized by the cells, and the $y$-axis was multiplied by $10^{4}$. For the $\mathrm{ALP}$ and calcium deposition, the data were compared to control (cells) and between each time. For cellular proliferation assays, the data were compared to pure $\mathrm{PCL}$. $\mathrm{N}=5$. $* * P<0.01$, $* * * P<0.001$, and $* * * * P<0.0001$ mean statistical differences. SEM of hFOBs cultivated on scaffolds after 7 days. (D) (i) PCL and (ii) magnified view. (E) (i) PCL-PEG and (ii) magnified view. (F) (i) PCL-PEG-GelMA without UV crosslinking and (ii) magnified view. (G) (i) PCL-PEG-GelMA after UV crosslinking and (ii) magnified view. The cells are spreading on all produced scaffolds presenting filopodium and cytoplasmic extension.

Abbreviations: ALP, alkaline phosphatase; GelMA, gelatin methacryloyl; hFOB, human osteoblasts; MTS, (3-(4,5-dimethylthiazol-2-yl)-5-(3-carboxymethoxyphenyl)-2-(4sulfophenyl)-2H-tetrazolium); NS, no significance; PCL, polycaprolactone; PEG, poly(ethylene glycol); SEM, scanning electron microscopy.

GelMA incorporation, an increase in proliferation of up to 2.5-fold was observed compared to pure PCL for all the time points $(P<0.05)$. Cell proliferation has a strong positive correlation with the hydrophilicity of a surface, ${ }^{45}$ and therefore the groups containing PEG and GelMA (each greatly hydrophilic) resulted in more cell proliferation compared to pure PCL (hydrophobic).

It has previously been reported that GelMA and PEG induced ECM calcification. ${ }^{46-52}$ For example, Turkkan et $a l^{53}$ showed that electrospun PCL:PEG with hydroxyapatite 
induced in vitro osteoblast mineralization. Tiwari et a ${ }^{18}$ electrospun different combinations of PCL and PEG and evaluated their potential to induce in vitro mineralization. However, the authors only investigated biocompatibility and in vitro mineralization using simulated body fluid. ${ }^{18}$ Differently, herein we investigated the ability of new scaffolds, fabricated from a unique combination of PCL:PEG:GelMA, to induce in vitro ECM calcification and calcium deposition when cultivated with human osteoblasts (hFOBs).

The cellular adhesion of hFOBs were evaluated by SEM (Figure 4D-G). The presence of a significant number of filopodium was clearly noticed, independent of the type of scaffolds analyzed (depicted in Figure 4E(ii), F(ii), and G(ii)). The hydrophobicity of PCL scaffolds did not inhibit hFOB adhesion (Figure 4D). The same behavior was observed after incorporation of PEG (Figure 4E, more hydrophilic). Meanwhile, after inclusion of GelMA, more filopodia were noticed (Figure 4F), indicating monolayer formation, especially after UV crosslinking (Figure 4E). Additionally, the ultrathin scaffold obtained after incorporation of PEG and GelMA could also possibly be another factor promoting cellular adhesion, where microfibrous fibers were obtained with only PCL (Figures $2 \mathrm{~A}-\mathrm{C}$ and $\mathrm{S} 1 \mathrm{~A}-\mathrm{C}$ ).

\section{Conclusion}

In summary, we report the preparation of electrospun scaffolds by a blend of PCL:PEG:GelMA polymers. Compared to previous reports, an improvement in efficacy was obtained due to the synergy of the desired properties of each polymer, including enhanced mechanical properties (stiffness) due to the presence of PCL, hydrophilicity due to the presence of PEG, and upregulation of hFOB cell functions from the incorporation of GelMA. The designed biomaterial also resulted in improved mechanical strength comparable to pure PCL. Furthermore, enhanced ALP activity, calcium deposition, and proliferation were obtained for our designed electrospun nanofibers compared to only PCL nanofibers.

\section{Acknowledgments}

AOL and FRM would like to thank the Sao Paulo Research Foundation (FAPESP, grants numbers: AOL 2015/09697-0 and FRM - 2016/00575-1), Coordination for the Improvement of Higher Education Personnel (CAPES, grant numbers AOL - 88881.120138/2016-01 and FRM - 88881.120221/2016-01), Brazilian National Council for Scientific and Technological Development (CNPq, AOL - 303752/2017-3 and FRM - 304133/2017-5), and to the Universidade Brasil for scholarships. SA gratefully acknowledges financial support from the Sweden-America Foundation (The Family Mix Entrepreneur foundation), Olle Engkvist Byggmästare Foundation, and Swedish Chemical Society (Bengt Lundqvist Memory Foundation) for a postdoctoral fellowship. AK acknowledges funding from the National Institutes of Health (AR057837, AR066193, EB022403, EB021148, HL137193, EB021857, AR070647, EB023052, CA214411, and EB024403). YSZ acknowledges funding from the National Institutes of Health (K99CA201603, R21EB025270, R21EB026175).

\section{Disclosure}

The authors report no conflicts of interest in this work.

\section{References}

1. Yoshimoto H, Shin YM, Terai H, Vacanti JP. A biodegradable nanofiber scaffold by electrospinning and its potential for bone tissue engineering. Biomaterials. 2003;24(12):2077-2082.

2. Schaap-Oziemlak AM, Kühn PT, van Kooten TG, van Rijn P. Biomaterial-stem cell interactions and their impact on stem cell response. RSC Adv. 2014;4(95):53307-53320.

3. Williams JM, Adewunmi A, Schek RM, et al. Bone tissue engineering using polycaprolactone scaffolds fabricated via selective laser sintering. Biomaterials. 2005;26(23):4817-4827.

4. Binulal NS, Natarajan A, Menon D, Bhaskaran VK, Mony U, Nair SV. PCL-gelatin composite nanofibers electrospun using diluted acetic acid-ethyl acetate solvent system for stem cell-based bone tissue engineering. J Biomater Sci Polym Ed. 2014;25(4):325-340.

5. Zhang Y, Ouyang H, Lim CT, Ramakrishna S, Huang ZM. Electrospinning of gelatin fibers and gelatin/PCL composite fibrous scaffolds. J Biomed Mater Res B Appl Biomater. 2005;72(1):156-165.

6. Fujihara K, Kotaki M, Ramakrishna S. Guided bone regeneration membrane made of polycaprolactone/calcium carbonate composite nano-fibers. Biomaterials. 2005;26(19):4139-4147.

7. Causa F, Netti PA, Ambrosio L, et al. Poly-epsilon-caprolactone/ hydroxyapatite composites for bone regeneration: in vitro characterization and human osteoblast response. J Biomed Mater Res A. 2006;76(1): $151-162$.

8. Ren K, Wang Y, Sun T, Yue W, Zhang H. Electrospun PCL/gelatin composite nanofiber structures for effective guided bone regeneration membranes. Mater Sci Eng C Mater Biol Appl. 2017;78:324-332.

9. Bose S, Roy M, Bandyopadhyay A. Recent advances in bone tissue engineering scaffolds. Trends Biotechnol. 2012;30(10):546-554.

10. Yi H, Ur Rehman F, Zhao C, Liu B, He N. Recent advances in nano scaffolds for bone repair. Bone Res. 2016;4:16050.

11. Jang JH, Castano O, Kim HW. Electrospun materials as potential platforms for bone tissue engineering. Adv Drug Deliv Rev. 2009;61(12): 1065-1083.

12. Pramanik S, Pingguan-Murphy B, Abu Osman NA. Progress of key strategies in development of electrospun scaffolds: bone tissue. Sci Technol Adv Mater. 2012;13(4):043002.

13. Zhu J. Bioactive modification of poly(ethylene glycol) hydrogels for tissue engineering. Biomaterials. 2010;31(17):4639-4656.

14. Pazarçeviren E, Erdemli Ö, Keskin D, Tezcaner A. Clinoptilolite/PCLPEG-PCL composite scaffolds for bone tissue engineering applications. J Biomater Appl. 2017;31(8):1148-1168.

15. Koupaei N, Karkhaneh A, Daliri Joupari M. Preparation and characterization of (PCL-crosslinked-PEG)/hydroxyapatite as bone tissue engineering scaffolds. J Biomed Mater Res A. 2015;103(12):3919-3926.

16. Yao R, He J, Meng G, Jiang B, Wu F. Electrospun PCL/Gelatin composite fibrous scaffolds: mechanical properties and cellular responses. J Biomater Sci Polym Ed. 2016;27(9):824-838. 
17. Yang G, Wang J, Wang Y, Li L, Guo X, Zhou S. An implantable active-targeting micelle-in-nanofiber device for efficient and safe cancer therapy. ACS Nano. 2015;9(2):1161-1174.

18. Tiwari AP, Joshi MK, Lee J, et al. Heterogeneous electrospun polycaprolactone/polyethylene glycol membranes with improved wettability, biocompatibility, and mineralization. Colloids Surf A Physicochem Eng Asp. 2017;520:105-113.

19. Shu XZ, Liu Y, Palumbo F, Prestwich GD. Disulfide-crosslinked hyaluronan-gelatin hydrogel films: a covalent mimic of the extracellular matrix for in vitro cell growth. Biomaterials. 2003;24(21):3825-3834.

20. Yue K, Trujillo-de Santiago G, Alvarez MM, Tamayol A, Annabi N, Khademhosseini A. Synthesis, properties, and biomedical applications of gelatin methacryloyl (GelMA) hydrogels. Biomaterials. 2015; 73:254-271.

21. Thakur T, Xavier JR, Cross L, et al. Photocrosslinkable and elastomeric hydrogels for bone regeneration. J Biomed Mater Res A. 2016; 104(4):879-888.

22. Echave MC, Sánchez P, Pedraz JL, Orive G. Progress of gelatin-based 3D approaches for bone regeneration. J Drug Deliv Sci Technol. 2017; 42:63-74.

23. Zhao X, Sun X, Yildirimer L, et al. Cell infiltrative hydrogel fibrous scaffolds for accelerated wound healing. Acta Biomater. 2017;49:66-77.

24. Nichol JW, Koshy ST, Bae H, Hwang CM, Yamanlar S, Khademhosseini A. Cell-laden microengineered gelatin methacrylate hydrogels. Biomaterials. 2010;31(21):5536-5544.

25. Klossner RR, Queen HA, Coughlin AJ, Krause WE. Correlation of chitosan's rheological properties and its ability to electrospin. Biomacromolecules. 2008;9(10):2947-2953.

26. Chakrapani VY, Gnanamani A, Giridev VR, Madhusoothanan M, Sekaran G. Electrospinning of type I collagen and PCL nanofibers using acetic acid. J Appl Polym Sci. 2012;125(4):3221-3227.

27. Fukushima K, Feijoo JL, Yang M-C. Comparison of abiotic and biotic degradation of PDLLA, PCL and partially miscible PDLLA/PCL blend. Eur Polym J. 2013;49(3):706-717.

28. Dallas $\mathrm{P}$, Niarchos D, Vrbanic D, et al. Interfacial polymerization of pyrrole and in situ synthesis of polypyrrole/silver nanocomposites. Polymer. 2007;48(7):2007-2013.

29. Seifpoor M, Nouri M, Mokhtari J. Thermo-regulating nanofibers based on nylon 6,6/polyethylene glycol blend. Fibers and Polymers. 2011;12(6):706-714

30. Chen H, Ma Q, Wang S, Liu H, Wang K, Morphology WK. Morphology, compatibility, physical and thermo-regulated properties of the electrospinning polyamide 6 and polyethylene glycol blended nanofibers. Journal of Industrial Textiles. 2016;45(6):1490-1503.

31. Shin H, Olsen BD, Khademhosseini A. The mechanical properties and cytotoxicity of cell-laden double-network hydrogels based on photocrosslinkable gelatin and gellan gum biomacromolecules. Biomaterials. 2012;33(11):3143-3152.

32. Li YF, Rubert M, Aslan H, et al. Ultraporous interweaving electrospun microfibers from PCL-PEO binary blends and their inflammatory responses. Nanoscale. 2014;6(6):3392-3402.

33. Xiao K, Zhai Y, Yu J, Ding B, Poly N-Structured. Nanonet-structured poly(m-phenylene isophthalamide)-polyurethane membranes with enhanced thermostability and wettability for high power lithium ion batteries. RSC Adv. 2015;5(68):55478-55485.

34. Guan J, Wagner WR, Synthesis WWR. Synthesis, characterization and cytocompatibility of polyurethaneurea elastomers with designed elastase sensitivity. Biomacromolecules. 2005;6(5):2833-2842.

35. Kwon IK, Kidoaki S, Matsuda T. Electrospun nano- to microfiber fabrics made of biodegradable copolyesters: structural characteristics, mechanical properties and cell adhesion potential. Biomaterials. 2005; 26(18):3929-3939.
36. Pant HR, Bajgai MP, Nam KT, Chu KH, Park S-J, Kim HY. Formation of electrospun nylon-6/methoxy poly(ethylene glycol) oligomer spider-wave nanofibers. Mater Lett. 2010;64(19):2087-2090.

37. Pant HR, Nam KT, Oh HJ, et al. Effect of polymer molecular weight on the fiber morphology of electrospun mats. J Colloid Interface Sci. 2011; 364(1):107-111.

38. Olszta MJ, Cheng X, Jee SS, et al. Bone structure and formation: A new perspective. Mater Sci Eng: R: Rep. 2007;58(3-5):77-116.

39. Correia TR, Ferreira P, Vaz R, et al. Development of UV cross-linked gelatin coated electrospun poly(caprolactone) fibrous scaffolds for tissue engineering. Int J Biol Macromol. 2016;93(Pt B):1539-1548.

40. Morouço P, Biscaia S, Viana T, et al. Fabrication of poly $(\varepsilon-$ caprolactone) scaffolds reinforced with cellulose nanofibers, with and without the addition of hydroxyapatite nanoparticles. Biomed Res Int. 2016;2016:1596157.

41. Vogler EA. Structure and reactivity of water at biomaterial surfaces. Adv Colloid Interface Sci. 1998;74(1):69-117.

42. Yuk H, Zhang T, Lin S, Parada GA, Zhao X. Tough bonding of hydrogels to diverse non-porous surfaces. Nat Mater. 2016;15(2):190-196.

43. Mizuno M, Kuboki Y. Osteoblast-related gene expression of bone marrow cells during the osteoblastic differentiation induced by type I collagen. J Biochem. 2001;129(1):133-138.

44. Koroleva A, Deiwick A, Nguyen A, et al. Osteogenic differentiation of human mesenchymal stem cells in 3-D Zr-Si organic-inorganic scaffolds produced by two-photon polymerization technique. PLoS One. 2015;10(2):e0118164.

45. Lampin M, Warocquier-Clérout, Legris C, Degrange M, Sigot-Luizard MF. Correlation between substratum roughness and wettability, cell adhesion, and cell migration. J Biomed Mater Res. 1997;36(1):99-108.

46. Byambaa B, Annabi N, Yue K, et al. Bioprinted osteogenic and vasculogenic patterns for engineering 3D bone tissue. Adv Healthc Mater. 2017;6(16):1700015.

47. Khayat A, Monteiro N, Smith EE, et al. GelMA-Encapsulated hDPSCs and HUVECs for dental pulp regeneration. J Dent Res. 2017;96(2): 192-199.

48. Chen X, Bai S, Li B, et al. Fabrication of gelatin methacrylate/ nanohydroxyapatite microgel arrays for periodontal tissue regeneration. Int J Nanomedicine. 2016;11:4707-4718.

49. Barati D, Shariati SRP, Moeinzadeh S, Melero-Martin JM, Khademhosseini A, Jabbari E. Spatiotemporal release of BMP-2 and VEGF enhances osteogenic and vasculogenic differentiation of human mesenchymal stem cells and endothelial colony-forming cells co-encapsulated in a patterned hydrogel. $J$ Control Release. 2016;223:126-136.

50. Aparnathi MK, Patel JS. Biodegradable gelatin methacrylate gel as a potential scaffold for bone tissue engineering of canine adipose-derived stem cells. J Stem Cells. 2016;11(3):111-119.

51. Jiang P, Mao Z, Gao C. Combinational effect of matrix elasticity and alendronate density on differentiation of rat mesenchymal stem cells. Acta Biomater. 2015;19:76-84.

52. Visser J, Gawlitta D, Benders KE, et al. Endochondral bone formation in gelatin methacrylamide hydrogel with embedded cartilage-derived matrix particles. Biomaterials. 2015;37:174-182.

53. Türkkan S, Pazarçeviren AE, Keskin D, Machin NE, Duygulu Ö, Tezcaner A. Nanosized CaP-silk fibroin-PCL-PEG-PCL/PCL based bilayer membranes for guided bone regeneration. Mater Sci Eng C Mater Biol Appl. 2017;80:484-493. 


\section{Supplementary materials Materials}

The polycaprolactone (PCL) (80,000), poly(ethylene glycol) (PEG) (Mw 8,000), gelatin (Type A, 300 bloom from porcine skin), methacrylic anhydride (MA), Alizarin red S, dimethyl sulfoxide, and Irgacure 2959 were purchased from SigmaAldrich (St. Louis, MO, USA). Hexafluoroisopropan-2-ol was purchased from Oakhood Chemical (St. Louis, MO, USA). Ethylenediaminetetraacetic acid, Dulbecco's PBS, and antibiotics were purchased from Sigma-Aldrich. AlphaMEM was supplied by Invitrogen. HyClone characterized FBS and precleaned microscope slides were obtained from Thermo Fisher Scientific (Waltham, MA, USA). 3-(4,5dimethylthiazol-2-yl)-5-(3-carboxymethoxyphenyl)-2-(4sulfophenyl)-2H-tetrazoli solution was provided by Promega (Fitchburg, WI).

\section{Procedure for the synthesis of gelatin methacryloyl (GelMA)}

GelMA was prepared in accordance with Nichol et al ${ }^{1}$ (Figure 1A). PBS $(100 \mathrm{~mL})$ was heated at $50^{\circ} \mathrm{C}$ and 10 $\mathrm{g}$ of gelatin (Type A, porcine skin) was dissolved and stirred for up to $1 \mathrm{~h}$. Next, $3 \mathrm{~mL}$ of methacrylate anhydride was dripped slowly and stirred in a closed system for $3 \mathrm{~h}$ $\left(50^{\circ} \mathrm{C}\right)$. Separately, PBS $(400 \mathrm{~mL})$ was preheated at $50^{\circ} \mathrm{C}$ and then mixed (final volume $500 \mathrm{~mL}$ ). The solution was divided in two portions and dialyzed using DI water for 7 days (dialysis tube, Sigma-Aldrich 12,000-14,000 Da, $40^{\circ} \mathrm{C}$ ). The DI water was changed twice per day. Finally, the solution was tranferred to falcon tubes, frozen at $-80^{\circ} \mathrm{C}$ for 5 days, and then lyophilized for 7 days. Proton nuclear magnetic resonance ( $\left.{ }^{1} \mathrm{HNMR}\right)$ detetermined the degree of methacryloyl substitution.
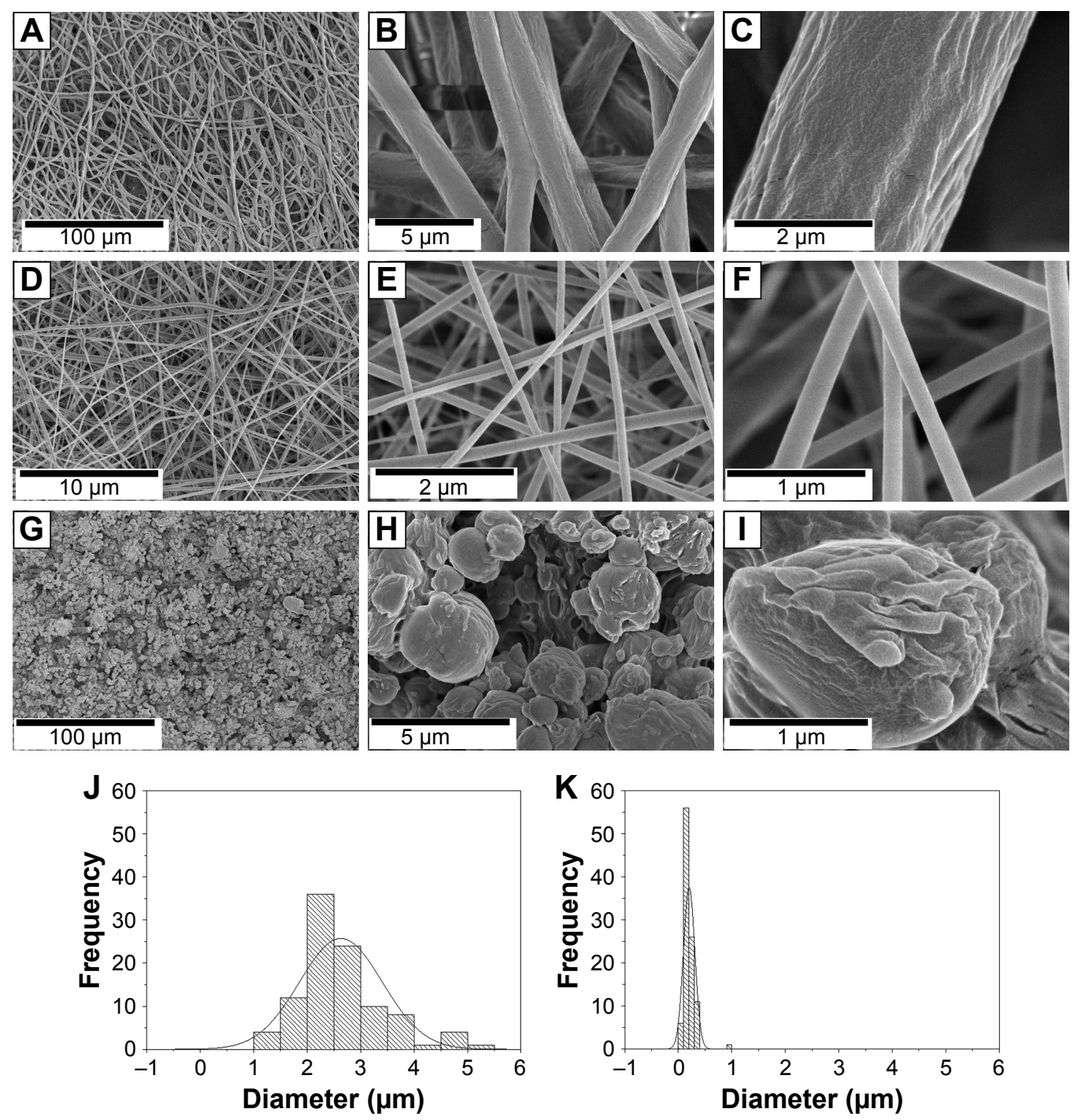

Figure SI (A-I) Morphology of electrospun (A-C) PCL fibers, (D-F) GelMA fibers and (G-I) PEG beads. (A, D, G) The distribution of diameters for (J) PCL and (K) GelMA fibers.

Abbreviations: GelMA, gelatin methacryloyl; PCL, polycaprolactone; PEG, poly(ethylene glycol). 
Table SI Liquids and surface tension components

\begin{tabular}{c|c|c|c}
\hline Surface tension data $(\mathbf{m N} / \mathbf{N})$ & $\gamma_{\mathrm{L}}^{\mathrm{D}}$ & $\gamma_{\mathrm{L}}^{\mathrm{P}}$ & $\gamma_{\mathrm{LV}}$ \\
\hline Water & 21.8 & 51.0 & 72.8 \\
Diiodomethane & 50.8 & 0.0 & 50.8 \\
\hline
\end{tabular}

Note: Data extracted from Zhang et al. ${ }^{5}$

\section{'H NMR analysis}

Thirty milligrams of GelMA was dissolved in $1 \mathrm{~mL}$ of deuterium oxide $\left(\mathrm{D}_{2} \mathrm{O}\right)$ and run at $37^{\circ} \mathrm{C}$. CD LABS 12.0 software analyzed the data. Comparison between methylene lysine protons $(2 \mathrm{H})$ around $2.8 \mathrm{ppm}$ (peak b) of gelatin and GelMA were used to determine the degree of methacryloyl substitution ( $66 \%$ by NMR analysis, Figure 1B).

\section{Preparation of the solutions}

PCL, PEG, and GelMA were separately dissolved (Figure 1C) for $12 \mathrm{~h}$ (using a closed system). A classical electrospinning process was coupled using: a syringe (BD Yale, $3 \mathrm{~mL}$ ), needle (Inbras, 24G), positive high voltage source (set to $17 \mathrm{kV}$, Nanospinner Machine, Inovenso), static stainless steel collector $(100 \times 100 \times 2 \mathrm{~mm})$ covered by aluminum foil, distance of $10 \mathrm{~cm}$ (needle tip to collector), infusion rate of $1 \mathrm{~mL} / \mathrm{h}$ (Harvard, PHD 2000), temperature at $23^{\circ} \mathrm{C}$, and humidity at $40 \%$.

\section{Crosslinking of scaffolds}

PCL:PEG:GelMA mats $(10 \times 10 \mathrm{~mm})$ (Figure 1C, Entry 4) were immersed in glutaraldehyde (25\% in DI water) for $12 \mathrm{~h}$. After, the mats were washed five times in a glycine solution $(15 \mathrm{mg} / \mathrm{mL}$ of DI water). Next, the mats were immersed in a photoinitiator solution (1.0 $\mathrm{g}$ of Irgacure, $10 \mathrm{~mL}$ of ethanol, absence of light) for $2 \mathrm{~h}$ and photocrosslinked for 10 min (365-nm UV light, OminiCure ${ }^{\circledR}-2000$ Series, $10 \mathrm{~cm}$ of working distance). Finally, the crosslinked PCL:PEG:GelMA were washed using the following sequence: ethanol $(3 \times)$, DI water $(3 \times)$ and dried overnight (vacuum). Figure 1D summarizes a possible mechanism after photocrosslinking.

\section{Characterization of scaffolds}

Micrographs were captured using an FEI Quanta 200, $3 \mathrm{kV}$, microscope. Previous to the analysis, a thin gold layer was evaporated for $10 \min (\sim 10 \mathrm{~nm})$. Attenuated total reflectance Fourier-transform infrared spectrometry (ATR-FTIR, Spotlight-400, Perkin Elmer) analyzed the vibrational chemical groups before and after UV photocrosslinking.

A goniometer (Krüss, Model DSA 100) operating in dynamic mode was used to measure the contact angle between the scaffold surface and air using water and diiodomethane. Two microliters of each liquid was dropped on each scaffold, and images were recorded after $1 \mathrm{~min}$. An N=5 for each sample was used.

The surface energy was calculated using interfacial tension through the Young's (equation 1$)^{2}$ and Young-Duprè equations (equation 2) using surface tension data from water and diiodomethane liquids (Table S1).

$$
\begin{gathered}
\operatorname{Cos} \varnothing \gamma_{\mathrm{LV}}=\gamma_{\mathrm{SV}}-\gamma_{\mathrm{SL}} \\
W_{\alpha}=\gamma_{\mathrm{LV}}(1+\cos \varnothing)=\gamma_{\mathrm{SV}}-\gamma_{\mathrm{SL}}
\end{gathered}
$$

where $\theta$ referred to contact angles between the liquid and solid, $\gamma_{\mathrm{LV}}$ (liquid/vapor), $\gamma_{\mathrm{SV}}$ (solid/vapor), $\gamma_{S L}$ (solid/liquid interfaces), and $W_{\alpha}$ (adhesion energy). Equations (1) and (2) were combined and used to calculate equation (3):

$$
\gamma_{\mathrm{LV}}(1+\cos \emptyset)=2 \sqrt{\gamma_{\mathrm{L}}^{\mathrm{p}} \gamma_{\mathrm{S}}^{\mathrm{p}}}+2 \sqrt{\gamma_{\mathrm{L}}^{\mathrm{D}} \gamma_{\mathrm{S}}^{\mathrm{D}}}
$$

showing polar components of the surface energy of $\gamma_{\mathrm{L}}^{\mathrm{P}}$ (liquid) and $\gamma_{\mathrm{S}}^{\mathrm{P}}$ (solid phases), $\gamma_{\mathrm{L}}^{\mathrm{D}}$ dispersive component of the surface energy of the liquid, and $\gamma_{\mathrm{S}}^{\mathrm{D}}$ of solid phases. Table $\mathrm{S} 2$ shows the surface energy calculated from equation $3.3,4$

Differential scanning calorimetry (TA Q20, TA Instruments) was used to identify the thermal properties of the produced scaffolds. For this, we used the first heating data, collected from $-60^{\circ} \mathrm{C}$ to $150^{\circ} \mathrm{C}$, at $10^{\circ} \mathrm{C} / \mathrm{min}$. The second heating data were also acquired at $10^{\circ} \mathrm{C} / \mathrm{min}$ until reaching $150^{\circ} \mathrm{C}$. The glass transition and the crystalline melting temperatures of the samples were obtained from the second heating and used to calculate the

Table S2 Contact angle and surface free energy calculated for the PCL:PEG:GelMA and PCL:PEG:GelMA-UV scaffolds ${ }^{\mathrm{a}}$

\begin{tabular}{|c|c|c|c|c|c|c|}
\hline Nanofiber formulation & \multicolumn{2}{|c|}{ Contact angle $\left(^{\circ}\right)$} & \multicolumn{2}{c|}{ Surface free energy $\left(\mathbf{m N ~ m}^{-1}\right)$} & \multicolumn{2}{c|}{$\gamma_{p}$} \\
\hline Sample & Water & Diiodomethane & Dispersive $\left(\gamma_{d}\right)$ & Polar $\left(\gamma_{p}\right)$ & $\left.\gamma_{d}+\gamma_{p}\right)$ \\
\hline PCL:PEG:GelMA & $25 \pm 2.8$ & $5 \pm 0.0$ & 40.6 & 30.8 & 71.4 & 0.43 \\
\hline PCL:PEG:GelMA-UV & $69 \pm 3.1$ & $5 \pm 0.0$ & 47.5 & 5.85 & 53.35 & 0.11 \\
\hline
\end{tabular}

Notes: ${ }^{a}$ Each mean value corresponds to the average value on three different samples. For PCL, the contact angle was $149^{\circ}$ (water).

Abbreviations: GelMA, gelatin methacryloyl; PCL, polycaprolactone; PEG, poly(ethylene glycol). 
degree of the crystallinity (Figure $3 \mathrm{G}$ and $\mathrm{H}$ ) by using equation (4).

$$
X_{c}(\%)=\frac{\Delta H_{m}-\Delta H_{c}}{\Delta H_{m}^{\infty} \times W} \times 100
$$

where $\Delta H_{c}=$ enthalpy of crystallization, $\Delta H_{m}=$ melting enthalpy of the sample, $\Delta H_{m}=$ melting enthalpy of a $100 \%$ crystalline sample, and $\Delta H_{m}=148 \mathrm{~J} / \mathrm{g}$ is the melting enthalpy of $100 \%$ crystalline PCL. $W$ is the height/mass fraction. ${ }^{6}$

A Dynamic Mechanical Analyzer (DMA Q800, TA Instruments) operating in tension mode (ASTM D 882-12 with some modifications) was used to measure the mechanical properties of the produced scaffolds before and after UV (elastic modulus, MPa; and elongation-at-break, expressed in a percentage) in tension mode. The scaffolds were then cut $(30 \times 5 \times 0.1 \mathrm{~mm})$ and preconditioned at $25^{\circ} \mathrm{C}$ and $50 \%$ humidity for $24 \mathrm{~h}$ before testing. Measurements were carried out at $25^{\circ} \mathrm{C}$ at a strain rate of $1 \mathrm{~mm} / \mathrm{min}(\mathrm{N}=3)$. The statistical difference was analyzed using Student's $t$-tests.

\section{Biological assays}

\section{Cell culture and sample sterilization}

Totally 5,000 cells $/ \mathrm{cm}^{2}$ of human osteoblast cells line (hFOB 1.19, bone-forming cells; Lonza, CRL-11372, second passage) were cultured using C27015 media (Osteoblast Basal Medium, Promocell GmbH), 1\% penicillin/streptomycin (P/S; Hyclone), and an Osteoblast Growth Medium Supplement Mix under standard cell culture conditions $\left(37^{\circ} \mathrm{C}\right.$, $5 \% \mathrm{CO}_{2}$, and $95 \%$ air). UV irradiation (30 min) was used to sterilize the scaffolds $\left(10 \mathrm{~mm}^{2}\right)$.

\section{Cell Proliferation assay}

An MTS CellTiter 96 ${ }^{\circledR}$ ((3-(4,5-dimethylthiazol-2-yl)-5-(3carboxymethoxyphenyl)-2-(4-sulfophenyl)-2H-tetrazolium), G3581; Promega Corporation) assay was used to determine cell density up to 21 days. The scaffolds were first immersed into 24-wells plates; 5,000 cells $/ \mathrm{cm}^{2}$ were placed onto scaffolds and cultivated for 14 days. The culture media was changed every 2 days. After 14 days, an MTS reagent (1:5 ratio with cell culture medium) was added to each well and incubated for $4 \mathrm{~h}$. Absorbance from each well was measured by a SpectraMax M3(MT05412) at $490 \mathrm{~nm}$, and a color change from pink to dark brown was seen. A standard curve was created with known numbers of cells to correlate absorbance to cell numbers.

\section{ALP assay}

A BioAssay QuantiChrom ${ }^{\mathrm{TM}}$ ALP Assay Kit (DALP-250) was used. After each incubation time (7, 14, and 21 days), $200 \mu \mathrm{L}$ of the assay buffer, $5 \mu \mathrm{L}$ of an acetate solution (final 5 $\mathrm{mM}$ ), and $2 \mu \mathrm{L}$ of the $p$-nitrophenylphosphate liquid substrate $(10 \mathrm{mM})$ were mixed and added to each 96-well assay. Two hundred microliters of DI water and the same volume of a calibration solution was transferred into separate wells of a clear bottom 96-well plate. Then, $50 \mu \mathrm{L}$ samples were carefully transferred into other wells, and $150 \mu \mathrm{L}$ of the working solution was pipetted into sample wells. The final reaction volume in the sample wells was $200 \mu \mathrm{L}$. The optical density was measured at $405 \mathrm{~nm}(t=0)$ and again after $4 \min (t=4 \mathrm{~min})$ on a plate reader using the supernatant.

\section{Calcium deposition}

Totally 5,000 cells $/ \mathrm{cm}^{2}$ were cultivated on the scaffolds for 7, 14, and 21 days. After each time, the scaffolds were washed three times using DI water. After, $1 \mathrm{~mL}$ of $0.6 \mathrm{M}$ hydrochloric acid was added to each well for $4 \mathrm{~h}$ while in a shaken incubator. Next, the resulting samples were collected after being centrifuged at $12,000 \mathrm{rpm}$ at $4^{\circ} \mathrm{C}$ for $3 \mathrm{~min}$, and the supernatants were collected. Next, the aliquots of the QuantiChrom Calcium Assay Kit (BioAssay Systems) were added. Finally, the contents were transferred to 96-well plates and placed into a SpectraMax M3 microplate reader (Molecular Device), and the absorbance was measured at $612 \mathrm{~nm}$. The values were obtained in absorbance according to the manufacturer's instructions. The absorbance was measured (612 nm) and compared to a standard curve constructed at the beginning of each trial.

\section{Cellular adhesion}

Totally 5,000 cells $/ \mathrm{cm}^{2}$ were cultivated on each scaffold for 7 days. After time, the scaffolds were washed ( $3 \times$ using PBS) and fixed in paraformaldehyde (4\%) at room temperature (20 min). Afterward, an ascending series of ethanol was used to dehydrate the samples. Finally, a thin gold layer was sputtered $(10 \mathrm{~nm})$ and micrographs were collected using a field emission gun scanning electron microscope (FEI Quanta $200,3 \mathrm{kV})$.

\section{Statistical analysis}

The experiments were analyzed in triplicate and repeated three times. ANOVA and Student's $t$-tests were used to determine the significance and statistical differences. The populations were obtained from a normal distribution. 


\section{References}

1. Nichol JW, Koshy ST, Bae H, Hwang CM, Yamanlar S, Khademhosseini A. Cell-laden microengineered gelatin methacrylate hydrogels. Biomaterials. 2010;31(21):5536-5544.

2. Young T. III. An essay of cohesion of fluids. Philos Trans R Soc London. 1809;95:65.

3. Van Oss CJ, Good RJ, Chaudhury MK. The role of van der Waals forces and hydrogen bonds in "hydrophobic interactions" between biopolymers and low energy surfaces. J Colloid Interface Sci. 1986; 111:378-390.
4. Flahaut E, Durrieu MC, Remy-Zolghadri M, Bareille R, Baquey C. Investigation of the cytotoxicity of CVVD carbon nanotubes towards human umblical vein endothelial cells. Carbon. 2006;44:1093-1099.

5. Zhang Y, Ouyang H, Lim CT, Ramakrishna S, Huang Z-M. Electrospinning of gelatin fibers and gelatin/PCL composite fibrous scaffolds. J Biomed Mater Res B Appl Biomater. 2005;72B(1):156-165.

6. Navarro-Baena V, Sessini V, Dominici F, Torre L, Kenny JM, Peponi L. Design and biodegradable blends based on PLA and PCL: from morphological, thermal and mechanical studies to shape memory behavior Polym Degrad Stab. 2016, 132, 97-108.
International Journal of Nanomedicine

\section{Publish your work in this journal}

The International Journal of Nanomedicine is an international, peerreviewed journal focusing on the application of nanotechnology in diagnostics, therapeutics, and drug delivery systems throughout the biomedical field. This journal is indexed on PubMed Central, MedLine, CAS, SciSearch $®$, Current Contents $\AA /$ Clinical Medicine,

\section{Dovepress}

Journal Citation Reports/Science Edition, EMBase, Scopus and the Elsevier Bibliographic databases. The manuscript management system is completely online and includes a very quick and fair peer-review system, which is all easy to use. Visit http://www.dovepress.com/ testimonials.php to read real quotes from published authors.

Submit your manuscript here: http://www.dovepress.com/international-journal-of-nanomedicine-journal 